\title{
The importance of the polymorphisms of the $A B C B 1$ gene in disease susceptibility, behavior and response to treatment in inflammatory bowel disease: A literature review
}

\author{
PawełW. Petryszyn ${ }^{A-E}$, Anna Wiela-Hojeńska ${ }^{A, E, F}$ \\ Department of Clinical Pharmacology, Wroclaw Medical University, Poland \\ A - research concept and design; $\mathrm{B}$ - collection and/or assembly of data; $\mathrm{C}$ - data analysis and interpretation; \\ $D$ - writing the article; $E$ - critical revision of the article; $F$ - final approval of the article
}

Address for correspondence

Paweł Petryszyn

E-mail: ppetryszyn@wp.pl

Funding sources

None declared

Conflict of interest

None declared

Received on April 24, 2016

Reviewed on July 20, 2018

Accepted on July 5, 2018

DOI

$10.17219 /$ acem/92936

\section{Copyright}

Copyright by Author(s)

This is an article distributed under the terms of the

Creative Commons Attribution Non-Commercial License

(http://creativecommons.org/licenses/by-nc-nd/4.0/)

\begin{abstract}
Crohn's disease (CD) and ulcerative colitis (UD) are the 2 common clinical subtypes of idiopathic inflammatory bowel disease (IBD) characterized by chronic inflammation of the gastrointestinal tract. The multifactorial etiology and pathogenesis of IBD is still unknown; however, the interaction between genetic, environmental and immunological factors seems to be crucial. A member of the adenosine triphosphate (ATP)-binding cassette family, P-glycoprotein, encoded by the human $A B C B 1$ gene, is among the most extensively studied transporters involved in drug disposition and effects. Single nucleotide polymorphisms (SNPS) located in exons 21, 26 and 12, i.e., G2677T/A, C3435T and C1236T, are of the greatest clinical importance. Functional defects of the intestinal epithelial barrier due to the lack of P-glycoprotein expression may constitute possible reasons for the development of colitis. Given that several drugs central to the therapy of IBD are also P-glycoprotein substrates, it has been hypothesized that its altered expression in IBD patients could modify the response to medical treatment. Nevertheless, there are conflicting reports of an association between these 3 SNPs and IBD. This article aims to review all relevant studies investigating the role of the polymorphisms of the $A B C B 1$ gene in disease susceptibility, behavior and response to treatment in IBD.
\end{abstract}

Key words: inflammatory bowel disease, MDR, P-glycoprotein 


\section{Introduction}

Crohn's disease (CD) and ulcerative colitis (UC) are the 2 common clinical subtypes of idiopathic inflammatory bowel disease (IBD) characterized by chronic inflammation of the gastrointestinal tract. They may occur in various geographic regions, however, with different frequency. They affect mainly citizens of developed countries from Europe and North America. A large multicenter study conducted in 1991-1993 in 12 European countries estimated the incidence rate of $\mathrm{UC}$ and $\mathrm{CD}$ to be 10.4 and 5.6 per 100,000 person-years, respectively. ${ }^{1}$ The incidence of IBD may have been changing over time, while the incidence of UC appears to remain stable, and a rise in incidence of CD has been observed. ${ }^{2,3}$ The peak incidence of IBD occurs between 15 and 40 years of age, with a possible $2^{\text {nd }}$ peak between 50 and 80 years of age. ${ }^{4}$

Ulcerative colitis is characterized by recurring episodes of inflammation limited to the mucosal layer of the colon. It involves the rectum and may spread proximally in a continuous fashion. Crohn's disease may involve the entire gastrointestinal tract from mouth to perianal area and is characterized by transmural inflammation and skip lesions, i.e., lesions appearing in a place surrounded by healthy mucosa. The transmural inflammation may lead to fibrosis and strictures as well as to microperforations and fistulae. Patients with UC usually present with bloody diarrhea. Associated symptoms include colicky abdominal pain, urgency, tenesmus, and fecal incontinence. Crampy abdominal pain, prolonged diarrhea and weight loss are the hallmarks of CD. Gross bleeding is less frequent than in UC. ${ }^{5}$

The underlying pathogenesis remains unclear but may involve persistent bacterial infection, defective mucosal barrier and imbalance in the regulation of the immune system. Epidemiological and family studies suggest that genetic factors play a significant role in determining susceptibility to IBD. Approximately $10-25 \%$ of individuals with IBD have a first degree relative with either CD or UC. ${ }^{6}$ In a study conducted among Danish twins with IBD, the concordance rate among monozygotic pairs was $58.3 \%$ for CD and $18.2 \%$ for UC. ${ }^{7}$ Inflammatory bowel disease appears to follow a non-Mendelian pattern of inheritance. It is likely that the aggregate effect at several loci contributes to the IBD phenotype. The first identified gene associated with CD was NOD2/CARD15 gene (nucleotide-binding oligomerization domain, caspase recruitment domain), localized on chromosome 16. Three mutations in the sequence of the NOD2/CARD15 gene, Arg702Trp, Gly908Arg and Leu1007fsinsC, appeared to be the factors strongly related to CD. Wild-type NOD2 protein activates nuclear factor kappa $B$, making it responsive to bacterial lipopolysaccharides; this induction is deficient in patients with the mutant form of NOD2. Patients with CD, who are the carriers of at least 1 of the 3 NOD2/CARD15 gene mutations, are at a higher risk for early onset and development of stenosis and small intestine involvement. ${ }^{8}$ The functional properties of the proteins encoded by the genes implicated in the susceptibility to IBD have enabled the identification of specific pathways important in the pathogenesis of IBD: ATG16L1 (the autophagy pathway), interleukin (IL)-17 and IL-23 receptor genes (pathways regulating adaptive immunity), and OCTN2 (the pathway regulating the epithelial function). ${ }^{9-11}$

P-glycoprotein has been the most extensively studied member of the adenosine triphosphate (ATP)-binding cassette superfamily encoded by the human $A B C B 1$ gene (previously known as $M D R 1$ ). P-glycoprotein is a phosphorylated and glycosylated protein that consists of 1280 amino acids and 2 homologous and symmetric sequences, each containing 6 transmembrane domains (TMDs), and a nucleotide-binding domain (NBD). P-glycoprotein functions as a transmembrane efflux pump, thereby moving drugs from the intracellular to the extracellular domain. Adenosine triphosphate hydrolysis provides the energy for active drug transport against steep concentration gradient. ${ }^{12}$ P-glycoprotein is expressed in several human tissues, including peripheral blood lymphocytes, epithelial cells in the small and large bowel, hepatocytes, pancreatic ductile cells, kidneys, adrenal glands, the epithelium of the brain choroids plexus, the capillaries of the brain, placenta, etc. Thus, it plays an important role in the excretion of xenobiotics and endogenous substrates via the canalicular membrane of hepatocytes into the bile, via the brush border membrane of enterocytes into the gut lumen and via the brush border membrane of proximal tubules into the urine. In the endothelial cells of the blood-brain barrier, P-glycoprotein prevents the entry of substrates into the central nervous system. ${ }^{13,14}$ P-glycoprotein transports a wide range of substances with diverse chemical structures, among them anticancer agents, cardiac drugs (e.g., digoxin, quinidine), HIV protease inhibitors, immunosuppressants (e.g., cyclosporine), and ß-blockers. Localized in gastrointestinal tract, it decreases their absorption and bioavailability. ${ }^{15}$ Interestingly, most substrates of P-glycoprotein are also metabolized by the isoenzyme CYP3A4. This is of particular importance, because P-glycoprotein and CYP3A4 are co-localized in the small intestine and liver, organs crucial for absorption, distribution and excretion of drugs. ${ }^{16}$

\section{$A B C B 1$ gene polymorphisms and IBD}

The $A B C B 1$ (MDR1) gene is located on chromosomal region $7 \mathrm{q} 21$ and consists of 28 exons encoding a protein composed of 1280 amino acids. It has been shown to be highly polymorphic, with 50 single nucleotide polymorphisms (SNPs) and 3 insertion/deletion polymorphisms reported so far. Three SNPs are currently considered to be the most clinically relevant, i.e., in exons 21 (G2677T/A), 26 (C3435T) and 12 (C1236T). ${ }^{17}$ Hoffmeyer et al. were the first to demonstrate a 2 -fold reduction in P-glycoprotein 
expression in duodenal biopsy samples among healthy Caucasian subjects homozygous for the mutant 3435T allele in comparison to subjects homozygous for the C3435 allele (wild-type). TT genotype was also shown to be associated with higher digoxin plasma concentrations after oral administration, suggesting greater drug absorption in individuals with low intestinal P-glycoprotein levels. ${ }^{18}$ These observations were only in apparent contradiction with the fact that $3435 \mathrm{C} \rightarrow \mathrm{T}$ mutation in exon 26 is a synonymous single-nucleotide polymorphism (i.e., does not alter the amino acid encoded). There is a linkage disequilibrium between SNPs in exon 26 (C3435T) and exon 21 (G2677T/A), suggesting that the observed differences in P-glycoprotein, initially attributed to the exon 26 SNP, may be the result of the associated tri-allelic polymorphism in exon 21 . The latter is a nonsynonymous single nucleotide polymorphism (i.e., one causing an amino acid change, Ala893Ser/Thr). ${ }^{19}$ It has also been recently shown that a synonymous SNP in exon $12(\mathrm{C} 1236 \mathrm{~T})$ is linked to the C3435T and G2677T/A SNPs. ${ }^{20}$

However, there are conflicting reports on an association between these 3 SNPs and IBD. The $A B C B 1$ gene is an attractive candidate for the pathogenesis of IBD and, perhaps, it may also condition response to therapy. Firstly, it is located in a region of the human genome (7q21) that was found to possibly harbor a disease gene involved in susceptibility to IBD. ${ }^{21}$ Its role in IBD was then investigated in a mouse knockout model (mdr1a-/-) in which developmentally normal mice spontaneously developed a colitis resembling UC in humans. They also developed a spontaneous colitis when maintained under specific pathogen-free conditions. The colitis was prevented and reversed with the administration of antibiotics, suggesting that the intestinal flora is necessary to initiate and perpetuate the inflammation. ${ }^{22}$ All this suggests that functional defects of the intestinal epithelial barrier (in terms of both loss of the xenobiotic efflux mechanism and host-bacteria interaction) due to the lack of P-glycoprotein expression are possible reasons for the pathogenesis of colitis.

\section{C3435T polymorphism}

In the initial case-control study conducted in Germany by Schwab et al., investigating the C3435T polymorphism, an increase of the $\mathrm{T}$ allele and $\mathrm{TT}$ genotype frequencies was identified in 149 patients with UC, but not with CD, compared with controls $(\mathrm{p}=0.049$, odds ratio $(\mathrm{OR})=1.4$; $\mathrm{p}=0.005, \mathrm{OR}=2.1$, respectively). ${ }^{23}$ This finding has been replicated in several studies but in a handful of other works such observation was not evident. Ho et al. in a study conducted in Scotland reported a statistically significant association between UC and a higher frequency of the mutant $\mathrm{T}$ allele $(\mathrm{p}=0.02, \mathrm{OR}=1.28)$ and of TT genotype $(\mathrm{p}=0.04$, $\mathrm{OR}=1.60) .{ }^{24}$ Similarly, Farnood et al. observed in the Iranian population a higher risk of UC development for the $3435 \mathrm{~T}$ allele carriers and 3435TT homozygotes. ${ }^{25}$ In contrast, negative findings have been reported in large studies from Germany and the UK, ${ }^{26}$ North America, ${ }^{27}$ Slovenia, ${ }^{28}$ and Italy. ${ }^{29}$ Paradoxically, Urcelay et al. found a significant association between the wild CC3435 genotype and CD in Spanish patients $(\mathrm{p}=0.007)$, recognizing the $3435 \mathrm{~T}$ allele as a risk factor for UC, and the $3435 \mathrm{C}$ allele as a risk factor for CD. ${ }^{30}$ The meta-analysis of 9 studies (1743 UC cases, 2311 CD cases and 2931 controls in total) has confirmed an association between C3435T and UC, with an OR = 1.12 (95\% confidence interval (CI): 1.02-1.23). For CD, the pooled ORs were not significant for either the fixed-effect or the random-effects model. ${ }^{31}$ Similar results, i.e., a significant association of UC with T allele (OR $=1.17$, 95\% CI: 1.06-1.31) and TT genotype $(\mathrm{OR}=1.36,95 \% \mathrm{CI}: 1.05-1.76)$, were obtained in another meta-analysis. ${ }^{32}$

It is worth mentioning that Ho et al. undertook a genotype-phenotype analysis and estimated the risk rate of UC with the proximally spreading lesions (i.e., extensive colitis) as $1.70(\mathrm{p}=0.009)$ for the $3435 \mathrm{~T}$ allele carriers and as 2.64 ( $\mathrm{p}=0.003$ ) for the $3435 \mathrm{TT}$ homozygotes. ${ }^{24}$ Likewise, Ardizzone et al. found Italians carrying the mutant $3435 \mathrm{~T}$ allele to present a 3-fold increased risk for developing CD with ileocolonic localization as compared to individuals with the wild-type allele. ${ }^{33}$

\section{G2677T/A polymorphism}

Investigating another polymorphism of $A B C B 1$ gene, the tri-allelic G2677T/A SNP (Ala893Ser/Thr) in a multicenter North American cohort study, Brant et al. found a significant association of the G2677 allele (Ala893), known to decrease P-glycoprotein function, with IBD. ${ }^{27}$ An association with another allele of this SNP, i.e., 2677T (893Ser), was identified in UC patients $(\mathrm{p}=0.029)$ by Potočnik et al. in Slovenia. ${ }^{28}$ Conversely, Ho et al. did not find any relation between this polymorphism and IBD. ${ }^{24}$ In the study by Onnie et al., the $2677 \mathrm{~T}$ allele was significantly increased in British UC cases compared with controls (45.2\% vs $39.6 \% ; \mathrm{p}=0.034)$. In particular, the TT genotype was significantly associated with severe $\mathrm{UC}(\mathrm{OR}=1.90$; $95 \% \mathrm{CI}$ : $1.01-3.55)$ and the use of steroids in $\mathrm{UC}(\mathrm{OR}=1.77$; $95 \% \mathrm{CI}$ : 1.08-2.88). ${ }^{31}$ After pooling data from the available studies, the meta-analysis performed by Annese et al. found no significant relation between allele and genotype frequencies of the G2677T/A SNP and UC, as well as between CD and IBD as a whole. ${ }^{32}$

\section{Linkage disequilibrium and heterogeneity considerations}

As significant linkage disequilibrium has been observed between 3 SNPs (G2677T/A, C3435T and C1236T) in different populations, a haplotype analysis seems to be 
justified in IBD patients. In the study by Ho et al., a 2-locus haplotype (3435T/G2677) was significantly associated with UC ( $\mathrm{p}=0.03) .{ }^{24}$ On the other hand, Urcelay et al. found a trend towards an increased frequency of 2-locus 2677T/C3435 haplotype in CD patients. ${ }^{30}$ Onnie et al. did not discover any significant C3435T-G2677T/A haplotype association with either $\mathrm{CD}$ or $\mathrm{UC} .^{31}$ The advantage of haplotype analysis in comparison to analysis of single polymorphisms in complex diseases has been confirmed in the study by Potočnik et al. They found haplotype defined by T-T-T (1236T-2677T-3435T) alleles to be significantly associated with higher risk for refractory $C D$ ( $\mathrm{p}=0.044, \mathrm{OR}=3.1)$ and $\mathrm{UC}(\mathrm{p}=0.026, \mathrm{OR}=1.6)$, although using each of these SNPs separately resulted in association only at the border of significance. ${ }^{28}$

Reasons for the discrepancy among the abovementioned studies may lie in population heterogeneity, sample size, selection of control population, incomplete phenotype description, and the lack of statistical power to detect the moderate effect size. It has been proven that there is a significant heterogeneity of the allele frequencies in various populations. For example, the frequency of the C3435 allele has been reported as 43-54\% in Caucasians, 34-63\% in Asians and 73-90\% in Africans. The incidence of $\mathrm{C} / \mathrm{T}$ and C/C3435 genotypes in Africans is much higher than in other racial populations. ${ }^{34}$

\section{Response to pharmacotherapy}

Of interest, several drugs central to the therapy of IBD are also P-glycoprotein substrates like glucocorticoids, cyclosporine and methotrexate. ${ }^{32}$ The hypothesis that altered P-glycoprotein expression in IBD patients could modify the response to medical therapy was verified by Farrell et al. Compared with controls, the expression of P-glycoprotein in peripheral blood lymphocytes was significantly elevated in patients with $C D$ who required bowel resection and patients with UC who required proctocolectomy for failed medical therapy. However, Farrell et al. did not investigate the role of genetic variants of the $A B C B 1$ gene. $^{35}$ Conversely, Palmieri et al., who compared allele and genotype frequencies in 594 patients using systemic steroids and 297 patients taking immunosuppressive drugs, did not find any influence of both C3435T and G2677T/A polymorphisms on the response to therapy. ${ }^{29}$

\section{Polish population}

Two studies have recently been published investigating the importance of C3435T and C1236T polymorphisms in determining IBD susceptibility in a population from central Poland. The $1^{\text {st }}$, evaluating the C $3435 \mathrm{~T}$ polymorphism, comprised 108 patients with IBD (61 with UC and 47 with $\mathrm{CD}$ ) and 137 healthy volunteers. ${ }^{36}$ The $2^{\text {nd }}$, evaluating the $\mathrm{C} 1236 \mathrm{~T}$ polymorphism, comprised 85 patients with IBD (45 with UC and 40 with CD) and 70 healthy volunteers. ${ }^{37}$ The identification of the polymorphisms in the $A B C B 1$ gene was carried out using the polymerase chain reaction - restriction fragment length polymorphism (PCR-RFLP) method. In both studies, the observed differences in genotype and allele frequencies were not significant. However, $3435 \mathrm{CC}$ genotype and $3435 \mathrm{C}$ allele carriers were present more frequently among IBD patients than in controls $(\mathrm{OR}=1.72,95 \% \mathrm{CI}: 0.95-3.12$ and $\mathrm{OR}=1.35,95 \% \mathrm{CI}$ : $0.94-1.93$, respectively). ${ }^{36}$ In parallel, $1236 \mathrm{CT}$ genotype and $1236 \mathrm{~T}$ allele carriers were more frequent in IBD patients compared to controls $(\mathrm{OR}=1.26,95 \% \mathrm{CI}$ : 0.66-2.42 and OR $=1.08$, 95\% CI: 0.41-2.14, respectively). ${ }^{37}$ Neither G2677T/A polymorphism nor the impact of G2677T/A, C3435T and C1236T polymorphisms on disease behavior and response to therapy in IBD have been explored so far in Poland. It is worth noting that even in our country a substantial heterogeneity of the allele frequencies in relation to the $A B C B 1$ gene has been observed. For example, the frequency of the $3435 \mathrm{CC}, 3435 \mathrm{CT}$ and $3435 \mathrm{TT}$ genotype was $23.3 \%, 56.3 \%$ and $20.4 \%$, and $42.0 \%$, and $41.0 \%$ and $17.0 \%$, respectively, in subjects originating from Western Pomerania and Łódź region. ${ }^{38,39}$ There has been so far no study determining the importance of the polymorphisms of the $A B C B 1$ gene in pediatric onset IBD. It seems equally challenging to evaluate the $A B C B 1$ gene expression in the tissues of the gastrointestinal tract, because, as was stated by Yacyshyn et al., intra-epithelial, lamina propria and peripheral blood lymphocytes may demonstrate different gene expression and activity of its product, P-glycoprotein. ${ }^{40}$

\section{References}

1. Shivananda S, Lennard-Jones J, Logan R, et al. Incidence of inflammatory bowel disease across Europe: Is there a difference between north and south? Results of the European Collaborative Study on Inflammatory Bowel Disease (EC-IBD). Gut. 1996;39(5):690-697.

2. Gollop JH, Phillips SF, Melton LJ $3^{\text {rd }}$, Zinsmeister AR. Epidemiologic aspects of Crohn's disease: A population-based study in Olmsted County, Minnesota, 1943-1982. Gut. 1988;29(1):49-56.

3. Loftus EV Jr, Silverstein MD, Sandborn WJ, Tremaine W, Harmsen W, Zinsmeister AR. Ulcerative colitis in Olmsted County, Minnesota, 1940-1993: Incidence, prevalence and survival. Gut. 2000;46(3):336-343.

4. Ekbom A, Helmick C, Zack M, Adami HO. The epidemiology of inflammatory bowel disease: A large, population-based study in Sweden. Gastroenterology. 1991;100(2):350-358.

5. Stenson WF, Korzenik J. Inflammatory bowel disease. In: Yamada T, Alpers DH, Laine L, Kaplowitz N, Owyang C, Powell DW, eds. Yama$d a^{\prime}$ T Textbook of Gastroenterology. $4^{\text {th }}$ ed. Philadelphia, PA: Lippincott Williams \& Wilkins Publishers; 2003:1699-1759.

6. Orholm M, Munkholm P, Langholz E, Nielsen $\mathrm{OH}$, Sørensen TI, Binder V. Familial occurrence of inflammatory bowel disease. N Engl J Med. 1991;324(2):84-88.

7. Orholm M, Binder V, Sørensen TI, Rasmussen LP, Kyvik KO. Concordance of inflammatory bowel disease among Danish twins. Results of a nationwide study. Scand J Gastroenterol. 2000;35(10):1075-1081.

8. Hampe J, Grebe J, Nikolaus S, et al. Association of NOD2 (CARD 15) genotype with clinical course of Crohn's disease: A cohort study. Lancet. 2002;359(9318):1661-1665.

9. Rioux JD, Xavier RJ, Taylor KD, et al. Genome-wide association study identifies new susceptibility loci for Crohn disease and implicates autophagy in disease pathogenesis. Nat Genet. 2007;39(5):596-604. 
10. Glocker EO, Kotlarz D, Boztug K, et al. Inflammatory bowel disease and mutations affecting the interleukin-10 receptor. $N$ Engl J Med. 2009;361(21):2033-2045.

11. Duerr RH, Taylor KD, Brant SR, et al. A genome-wide association study identifies IL23R as an inflammatory bowel disease gene. Science. 2006;314(5804):1461-1463.

12. Borst P, Evers R, Kool M, Wijnholds J. A family of drug transporters: The multidrug resistance-associated proteins. J Nat/ Cancer Inst. 2000;92(16):1295-1302.

13. Thiebaut F, Tsuruo T, Hamada H, Gottesman MM, Pastan I, Willingham MC. Cellular localization of the multidrug-resistance gene product P-glycoprotein in normal human tissues. Proc Natl Acad SciU SA. 1987;84(21):7735-7738.

14. Sugawara I, Kataoka I, Morishita Y, et al. Tissue distribution of P-glycoprotein encoded by a multidrug-resistant gene as revealed by a monoclonal antibody, MRK 16. Cancer Res. 1988;48(7):1926-1929.

15. Schwab M, Eichelbaum M, Fromm MF. Genetic polymorphisms of the human MDR1 drug transporter. Annu Rev Pharmacol Toxicol. 2003;43:285-307.

16. Watkins PB. The barrier function of CYP3A4 and P-glycoprotein in the small bowel. Adv Drug Deliv Rev. 1997;27(2-3):161-170.

17. Gottesman MM, Hrycyna CA, Schoenlein PV, Germann UA, Pas$\tan$ I. Genetic analysis of the multidrug transporter. Annu Rev Genet. 1995;29:607-647.

18. Hoffmeyer $S$, Burk $O$, von Richter $O$, et al. Functional polymorphisms of the human multidrug resistance gene: Multiple sequence variations and correlation of one allele with P-glycoprotein expression and activity in vivo. Proc Natl Acad Sci U S A. 2000;97(7):3473-3478.

19. Kim RB, Leake BF, Choo EF, et al. Identification of functionally variant MDR1 alleles among European Americans and African Americans. Clin Pharmacol Ther. 2001;70(2):189-199.

20. Illmer T, Schuler US, Thiede C, et al. MDR1 gene polymorphisms affect therapy outcome in acute myeloid leukemia patients. Cancer Res. 2002;62(17):4955-4962.

21. Satsangi J, Parkes M, Louis E, et al. Two stage genome-wide search in inflammatory bowel disease provides evidence for susceptibility loci on chromosomes 3, 7 and 12. Nat Genet. 1996;14(2):199-202.

22. Panwala $C M$, Jones JC, Viney JL. A novel model of inflammatory bowel disease: Mice deficient for the multiple drug resistance gene, MDR1A, spontaneously develop colitis. J Immunol. 1998;161(10):5733-5744.

23. Schwab M, Schaeffeler E, Marx C, et al. Association between the C3435T MDR1 gene polymorphism and susceptibility for ulcerative colitis. Gastroenterology. 2003;124(1):26-33.

24. Ho GT, Nimmo ER, Tenesa A, et al. Allelic variations of the multidrug resistance gene determine susceptibility and disease behavior in ulcerative colitis. Gastroenterology. 2005;128(2):288-296.

25. Farnood A, Naderi N, Moghaddam SJM, et al. The frequency of C3435T MDR1 gene polymorphism in Iranian patients with ulcerative colitis. Int J Colorectal Dis. 2007;22:999-1003.

26. Croucher PJ, Mascheretti S, Foelsch UR, Hampe J, Schreiber S. Lack of association between the C3435T MDR1 gene polymorphism and inflammatory bowel disease in two independent Northern European populations. Gastroenterology. 2003;125(6):1919-1920.

27. Brant SR, Panhuysen $\mathrm{Cl}$, Nicolae D, et al. MDR1 Ala893 polymorphism is associated with inflammatory bowel disease. Am J Hum Genet. 2003;73(6):1282-1292.

28. Potočnik U, Ferkolj I, Glavac D, Dean M. Polymorphisms in multidrug resistance 1 (MDR1) gene are associated with refractory Crohn disease and ulcerative colitis. Genes Immun. 2004;5(7):530-539.

29. Palmieri $O$, Latiano $A$, Valvano $R$, et al. Multidrug resistance 1 gene polymorphisms are not associated with inflammatory bowel disease and response to therapy in Italian patients. Aliment Pharmacol Ther. 2005;22(11-12):1129-1138.

30. Urcelay E, Mendoza JL, Martin MC, et al. MDR1 gene: Susceptibility in Spanish Crohn's disease and ulcerative colitis patients. Inflamm Bowel Dis. 2006;12(1):33-37.

31. Onnie CM, Fisher SA, Pattni R, et al. Associations of allelic variants of the multidrug resistance gene ( $A B C B 1$ or MDR1) and inflammatory bowel disease and their effects on disease behavior: A case-control and meta-analysis study. Inflamm Bowel Dis. 2006;12(4):263-271.

32. Annese V, Valvano MR, Palmieri O, Latiano A, Bossa F, Andriulli A. Multidrug resistance 1 gene in inflammatory bowel disease: A metaanalysis. World J Gastroenterol. 2006;12(23):3636-3344.
33. Ardizzone S, Maconi G, Bianchi V, et al. Multidrug resistance 1 gene polymorphism and susceptibility to inflammatory bowel disease. Inflamm Bowel Dis. 2007;13(5):516-523.

34. leiri I, Takane H, Otsubo K. The MDR1 ( $A B C B 1$ ) gene polymorphism and its clinical implications. Clin Pharmacokinet. 2004;43(9):553-576.

35. Farrell RJ, Murphy A, Long A, et al. High multidrug resistance (P-glycoprotein 170) expression in inflammatory bowel disease patients who fail medical therapy. Gastroenterology. 2000;118(2):279-288.

36. Dudarewicz M, Barańska M, Rychlik-Sych $M$, Trzciński R, Dziki A, Skrętkowicz J. C3435T polymorphism of the $A B C B 1 / M D R 1$ gene encoding P-glycoprotein in patients with inflammatory bowel disease in a Polish population. Pharmacol Rep. 2012;64(2):343-350.

37. Dudarewicz $M$, Barańska $M$, Rychlik-Sych $M$, et al. The importance of $C 1236 \mathrm{~T}$ polymorphism in the $A B C B 1 / M D R 1$ gene in assessment of susceptibility to inflammatory bowel diseases in the Polish population. Prz Gastroenterol. 2013;8(1):38-43.

38. Droździk M, Białecka M, Myśliwiec K, Honczarenko K, Stankiewicz J, Sych Z. Polymorphism in the P-glycoprotein drug transporter MDR1 gene: A possible link between environmental and genetic factors in Parkinson's disease. Pharmacogenetics. 2003;13(5):259-263.

39. Jamroziak K, Balcerczak E, Młynarski W, Mirowski M, Robak T. Distribution of allelic variants of functional C3435T polymorphism of drug transporter MDR1 gene in a sample of Polish population. Pol J Pharmacol. 2002;54(5):495-500.

40. Yacyshyn B, Maksymowych W, Bowen-Yacyshyn MB. Differences in P-glycoprotein-170 expression and activity between Crohn's disease and ulcerative colitis. Hum Immunol. 1999;60(8):677-687. 